Vol. 1 No. 2 (Mei 2021) (345-355)

$\underline{\text { http://ejournal.stkip-pgri-sumbar.ac.id/index.php/horizon }}$

\title{
KEHIDUPAN SOSIAL EKONOMI MASYARAKAT DESA KERSIK TUO SEBAGAI DESA PENYANGGA PARIWISATA GUNUNG KERINCI (2013-2018)
}

\author{
Febri Yonata, Zulfa, Livia Ersi \\ Program Studi Pendidikan Sejarah STKIP PGRI Sumatera Barat \\ febriyonatharyo@gmail.com
}

\begin{abstract}
This research generally discuss about social and economic conditions in Kersik TuoVillage as a Tourism Destination, were Kerinci mountain become favorite choice for montain climber, which one this icons located in Kerinci Seblat National Park area with an altitude of 3805 Masl. Kersik Tuo Village has long been a center of mobility as well as a transit point for tourists, and also the people also provides various kinds of needed for tourists. There are many of social and economic relations that exist in the community, for this reason the people of Kersik Tuo Village do not really see a tourism as a field to advance the community's economy. The purpose of this research is to explain the socio-economic conditions of the Mount Kerinci tourism support community in Kersik Tuo in 2013-2018 and to explain the people's role of Kersik Tuo in Supporting Mount Kerinci Tourism. The research method that used in this research is historical research, that combines Heuristik, critically resources, Interpretation and historiography. The result of this research, Kersik Tuo Village is a village that nearest from Kerinci mountain. The population in Kersik Tuo mostly in agriculture and trade. The tourism have an effect for Social $\neg$ - Economic conditions of the Tersik Tuo society as a support for Mount Kerinci Tourism and always advancement from 2013 until 2018. This is added with people that participating in sector, like a service industry, trademark, etc. The people realize that the tourism is important to developed Kersik Tuo village.
\end{abstract}

Keyword: The Social Economic, Kerinci, Tourism.

PENDAHULUAN

Pariwisata dapat dipandang sebagai pendorong dalam sosial dan ekonomi seperti meningkatkan kegiatan pembangunan, membuka lapangan pekerjaan baru dan dapat meningkatkan pendapatan masyarakat serta pendapatan asli daerah, apabila di kelola dengan baik, dalam perkembangannya pariwisata harus di 
iringi dengan berkembangnya sumber daya manusia yang berkualitas dan profesional (Rai, 2014). Kabupaten Kerinci merupakan kabupaten yang memiliki keindahan di bidang panorama wisata di Provinsi Jambi, memiliki banyak pesona wisatanya di antaranya Gunung Kerinci, Danau Gunung Tujuh, Danau Kerinci, Perkebunan Teh dan beberapa objek wisata air terjun. Gunung Kerinci merupakan salah satu tujuan utama dari wisatawan yang datang baik domestik maupun mancanegara (BPS, 2015).

Masyarakat Desa Kersik Tuo tidak banyak yang bergantung pada objek wisata alam Gunung Kerinci sebagai mata pencarian utama, baik dari segi perdagangan kerajinan yang bernilai ekonomis seprti cindramata dll atau jasa, jasa disini seperti halnya, homestay atau rumah singgah dan berkaitan dengan industri jasa seperti jasa transportasi, pemandu wisata (guide), buruh angkut perlengkapan (porter) dan bahkan jasa tour leader, baik yang tergabung dalam sebuah komunitas yang tercatat sebagai mitra TNKS atau Industri jasa independen, Masyarakat Desa Kersik Tuo sebagian besar berprofesi sebagai petani Sementara Desa Kersik Tuo sendiri merupakan akses utama menuju pintu rimba atau gerbang pendakian unung Kerinci.

\section{METODE PENELITIAN}

Seperti halnya kebanyakan karyakarya sejarah sosial dan ekonomi, Penelitian ini termasuk penelitian sejarah, untuk mendapatkan data-data yang relevan dengan permasalahan penelitian, digunakan teknik-teknik penelitian yang sesuai dengan kaidahkaidah penelitian sejarah, yaitu heuristik, kritik sumber, interpretasi, dan historiografi (Helius. 2012).

Heuristik merupakan proses mencari dan mengumpulkan data dari sumber yang relevan baik itu primer maupun sekunder. Sumber primer terdapat dari arsip dan dokumen. Disamping itu, informasi yang diperoleh dari hasil, Kritik sumber 
Vol. 1 No. 2 (Mei 2021) (345-355)

http://ejournal.stkip-pgri-sumbar.ac.id/index.php/horizon

merupakan menyeleksi sumber yang bersifat ekstern yaitu bagaimana untuk melihat keaslian sumber, sedangkan kritik intern merupakan kritik untuk meneliti isi dari informasi sejarah yang terkandung didalamnya. Interpretasi merupakan memilahmilah atau membedah sehingga menjadi butir-butir informasi yang sebenarnya atau sudah diuji melalui saringan kritik sumber dengan cara melakukan pengelompokan sumber berdasarkan objek yang diteliti, Setelah melalui tahap analisis dilanjutkan dengan tahap sintesis yaitu merangkai atau menghubungkan data dari informasi yang melibatkan interpretasi guna merekonstruksi peristiwa-peristiwa yang dialami Masyarakat. Setelah semua data terkumpul baru dilakukan historiografi yaitu menuliskan temuan penelitian kedalam bentuk laporan yang utuh dan sesuai dengan kaidahkaidah penelitian sejarah (Zed, 1999).

\section{HASIL DAN PEMBAHASAN}

Desa kersik tua merupakan desa dengan mata pencarian masyarakatnya yang beragam, salah satu yang menjadi mayoritas dan banyak di geluti masyarakat adalah bertani. Terdapat banyak pola hubungan sosial yang terdapat didalam bidang ini yang sangat bergantung dengan kondisi masing wilayah termasuk kondisi usaha pertanian, hubungan sosial dan ekonomi biasanya terjalin antara petani dengan pedagang, pengepul dan seterusnya, dengan alasan ini masyarakat Desa Kersik Tuo tidak begitu memandang sebuah objek wisata sebagai sebuah ladang untuk memajukan prekonomian masyarakat.

Keberadaan Gunung Kerinci yang merupakan Gunung tertinggi di Pulau Sumatra menjadi daya tarik bagi parawisatan untuk datang berkunjung, wisatawan datang tidak setiap hari dan cendrung tidak menentu, pengunjung dalam negri meningkat pada hari-hari tertentu seja 
seperti pada akhir tahun dan hari-hari libur nasional, begitu pula dengan kedatangan wisatawan mancanegara yang datang dengan jumlah yang cukup besar antara bulan juli-agustus dan pada akhir tahun atau mendekati tahun baru (Zetra, 2018).

Pada rentan waktu 2013-2015 tidak begitu banyak perkembangan dalam usaha masyarakat yang menjadi penopang pariwisata Gunung Kerinci, atau dapat diartikan sedikit usaha yang terfokus untuk menyangga berjalannya pariwisata Gunung Kerinci, tahun 2013 pasca erupsi gunung kerinci pada 2009, yang mengakibatkan menurunnya jumlah wisatawan di tahun-tahun berikutnya, dampak ini dirasakan bagi sebagian masyarakat yang melakukan aktivitas di bidang wisata, seperti pemandu, penyewaan penginapan dan transportasi. Namun demikian tidak menyebabkan penurunan yang derastis terhadap perekonomian lokal, hal ini karena masyarakat menjadikan profesi di bidang pariwisata sebagai sambilan di samping profesi utama sebagai petani dan berdagang, pada tahun 2013-2015 pemandu wisata (Tour Guide) juga belum begitu banyak hanya beberapa orang saja dengan upah Rp. 150.000/ hari dan Rp.200.000 untuk pengantar barang (Porter) dengan minimal perjalan 2 hari.

Mayoritas pengunjung atau wisatawan yang datang seperti mahasiswa dan pelajar yang meningkat pada masi libur, dibandingkan dengan wisata alam gunung seperti di Pulau Jawa yang telah menerapkan desa sadar wisata sejak 2013, dimaksudkan untuk seiring jumlah populasi yang tambah masyarakat dapat menyediakan lapangan perkerjaan lokal di bidang wisata untuk kemajuan ekonomi dan sosial daerah tersebut, dan dibantu oleh dinas terkait sepertihalnya taman nasional dan pemda, untuk membimbing masyarakat dalam membangun desa sadar wisata, namun hal demikian belum terjadi di 
kawasan taman wisata gunung kerinci, hal tersebut menjadi salah satu faktor yang mempengaruhi tidak adanya perkembangan di bidang usaha penyangga pariwisata pada tahun 2013.

Pada Tahun 2014 peningkatan jumlah wisatawan di taman wisata alam Gunung Kerinci turut membawa dampak bagi pengusaha jasa wisatawan seperti hanya bertampahnya pendapatan, jasa penyewaan penginapan seperti homestay, pedagang kelontong,pasar tradisional, dan meningkatnya pendapatan negara melalui tiket masuk taman wisata Gunung Kerinci yang merupakan PNBP, juga transaksi wisatawan di bank yang ada di Desa Kersik Tua, juga mulai bertambahnya jumlah pemandu dan porter di kawasan Gunung Kerinci, masyarakat desa Kersik Tuo mulai memandang hal tersebut sebagai peluang dalam mengembangkan usaha dengan target pasar para wisatawan yang datang.
Pada tahun 2015 terjadi peningkatan yang signifikan dari wisatawan terjadi, hal ini di dasari promosi secara tidak langsung oleh sebuah industri perfilman yang mengangkat tema perjalanan wisata gunung di pulau jawa, dampak tersebut menyebar hingga di wisata Alam di Sumatra khususnya Gunung Kerinci yang merupakan gunung dengan puncak tertinggi di pulau Sumatra, dengan meningkatnya jumlah wisatwan menyebabkan bertambahnya jumlah fasilitas yang ada untuk mendukung berjalannya pariwisata, seiring dengan perkembangan desa Kersik Tuo sebagai mobilitas atau transit bagi wisatawan yang hendak melakukan perjalanan wisata di Gunung Kerinci, juga di pengaruhi pola pemukiman, menjadi berkembangnya usaha di bidang perdagangan, sementara di bidang usaha atau jasa pariwisata, beberapa masyarakat desa Kersik Tua yang merupakan penggiat alam mulai memandang adanya sebuah potensi 
untuk sebuah profesi yang dapat menambah peluang pekerjaan, seperti halnya pemandu wisa, (tour guide) dan pegantar barang (porter) pada tahun 2015 ada beberapa usaha jasa yang mulai terbentuk dan berjalan Pertama Terbentuknya Komunitas Pemandu Kedua Tersedianya souvenir dan kebutuhan wisatawan

Memasuki awal tahun 2016 perkembangan pariwisata gunung kerinci semakin terlihat, banyak masyarakat desa Kersik Tua yang mulai memandang wisata sebagai sumber pendapatan lokal dan mampu menyangga perekonomian, dampak peningkatan wisatawan di tahun sebelumnya terasa sampai dengan tahun 2016 dengan puncak terjadi pada 2017.

Pada tahun 2016 peningkatan pendapatan ekonomi dari sektor pariwisata khususnya Gunung Kerinci sendiri dapat dirasakan secara langsung bagi masyarakat Desa kersik tua, hal tersebut dibuktikan dengan bertambahnya pendapatan masyarakat seperti pendapatan dan jumlah pemandu wisata dan porter di Gunung Kerinci yang mempunyai kedai kelontong disepanjang jalan lintas desa Kersik Tua, juga bertambahnya jumlah toko yang menyediakan souvenir bagi parawisatawan.

Pada september 2017 Kepala Balai Besar Taman Nasional Kerinci Seblat dengan Bupati Kerinci melakukan kerjasama dibidang penguatan fungsi kawasan konservasi Taman Nasional Kerinci Seblat, khususnya mengenai Pengembangan Objek Wisata Gunung Tujuh Dan Gunung Kerinci Pada Zona Pemanfaatan Taman Nasional Kerinci Seblat.

Pada Tahun 2018 seiring dengan bertambahnya jumlah pengunjung dan masyarakat yang mendukung berlangsungnya pariwisata gunung kerinci, terdapat beberapa faktor yang turut mempengaruhi keberhasilan pengelolaan wisata Alam gunung kerinci diantaranya adalah SDM kelompok, dukungan dan partisipasi 
masyarakat sekitar, promosi wisata oleh para wisatawan dan tour travel. Kegiatan BBTNKS yang melibatkan kelompok masyarakat, Potensi hutan, dan landscape TNKS yang terjaga dengan Baik, fasilitas Pendakian memadai, jalur pendakian berada di zona pemanfaatan TNKS dan dukungan dari balai dan pemerintah desa. Standar Operasi Prosedur atau SOP yang di terapkan pada September 2018 menjadi alat penilaian kinerja berdasarkan indikator-indikator tehnik, dengan penerapan SOP pendakian Gunung Kerinci ini diharapkan dapat keanekaragaman hayati dan ekosistem Gunung Kerinci. Peranan Desa Kersik Tuo dalam menyangga pariwisata dalam kurun waktu 2013-2018, hal tersebut semakin bertambah karena beberapa tahun terahir pemerintah dan BBTNKS menerapkan sebuah sistem kemitraan, antara pemerintah, balai besar, penginapan, organisasi pemandu dan juga melibatkan masyarakat, seperti halnya pembangunan fasilitas sepanjang jalur pendakian gunung kerinci, melakukan pelatihan terhadap pemilik jasa yang di anggap dapat menunjang pariwisata, khususnya pemilik penginapan dan pemandu wisata, Hal tersebut di harapkan dapat menjadi modal untuk kemajuan pariwisata Gunung Kerinci, khususnya untuk wilayah Desa Kersik Tuo terfokus pada pengembangan sumber daya manusia untuk menunjang pariwisata Gunung kerinci dan lainya yang masuk dalam zona pemanfaatan. usaha masyarakat dalam menyangga pariwisata pariwisata Gunung Kerinci diantaranya Pertama jasa penginapan, Jasa penginapan di Desa Kersik Tuo sudah ada sejak tahun 1990 hal tersebut di perkuat oleh adanya tanggal pembuatan pembangunan salah satu Homesty, seiring dengan kebutuhan pengunjung dan perkembangan pariwisata saat ini terdapat homesty, hotel, bahkan rumah warga yang dimanfaatkan sebagai penginapan. Kedua. usaha 
kuliner / rumah makan atau restoran adalah satu jenis usaha jasa pangan yang bertempat disebagian atau seluruh bangunan permanen, dilengkapi dengan peralatan dan perlengkapan untuk proses pembuatan, penyajian dan penjualan makanan serta minuman untuk umum yang datang berkunjung. Ketiga pedagang souvenir Pedagang cindramata di Desa Kersik Tuo tidak begitu banyak, hanya beberapa saja beberapa toko cindra mata atau souvenir, beberapa toko cindramata dapat di temukan di beberapa penginapan desa saja dan toko perlengkapan pendakian, Bagi para pemilik toko cindramata, oleh-oleh memasok barang dari berbagai daerah sekitar Desa Kersik Tuo bahan dari luar Kabupaten Kerinci, dan hanya beberapa pedagang souvenir yang merupakan masyarakat Desa Kersik Tuo. Keempat Transportasi Keberadaan alat transportasi di setiap wilayah tentu sangat di perlukan guna untuk mempermudah dalam melakukan aktivitas dalam kehidupan sehari-hari. Kerinci juga salah satu daerah yang meningkatkan pelayanan di bidang trasportasi tak hanya terfokus dengan dengan jasa trasportasi saja juga pelayanan tersebut merjadi sarana penyangga pariwisata. Kelima biro jasa perjalanan suatu perusahaan dapat disebut sebagai biro perjalan wisata apabila kegiatan utama perusahaan tersebut ditekankan pada perencanaan dan penyelenggaraan perjalanan wisata atau paket wisata atas inisiatif sendiri dan tanggung jawab sendiri dengan tujuan mengambil keuntungan dari penyelenggaraan perjalanan tersebut (Gde \& Ketut, 2015). Dalam hal ini desa biro jasa perjalanan, di Kerinci sendiri terdapat beberapa biro perjalanan wisata yang memiliki izin, namun untuk desa kersik tuo tidak di ketahui dengan pasti tentang adanya biro jasa perjalanan yang memiliki perizinan, dan yang terlibat diantaranya adalah, guide/pemandu wisata, porter/pengantar barang, 
penyewaan perlengkapan. Keenam kedai kelontong dari lapangan diketahui bahwa pada awalnya hanya menjual bahan-bahan kebutuhan rumah tangga saja saja tapi dalam beberapa tahun belakangan juga menjual beberapa kebutuhan bagi parawisatawan, seperti halnya jenis makanan yang sering di bawa oleh para wisatawan, tak hanya itu kebutuhan yang biasa di tanyakan para wisatawan juga di jual di kebanyakan kedai kelontong. Dan yang terahir adalah Pasar Tradisional Pasar Kersik Tuo mempunyai tempat yang strategis yaitu terletak pada jalan raya lintas Sumatera dengan adanya pasar tradisional memudahkan para pengunjung mendapatkan kebutuhan yang di perlukan selama melakukan kegiatan berwisata, seperti halnya untuk memenuhi kebutuhan bekal dalam pejalanan mendaki gunung, dengan begitu juga akan menambah pendapatan masyarakat Desa Kersik Tua, Kedatangan wisatawan untuk berbelanja kebutuhan pasti ada setiap kegiatan pasar pada hari Sabtu pagi sampai dengan sore hari, bahkan terdapat beberapa artis ibu kota yang datang untuk mendaki Gunung Kerinci dan menyempatkan diri untuk belanja kebutuhan di pasar desa Kersik tua.

\section{KESIMPULAN}

Berdasarkan uraian dan pemaparan sejarah sosial ekonomi masyarakat penyangga pariwisata Wisata Alam Gunung Kerinci di Desa Kersik tua, Desa Kersik Tuo merupakan salah satu unit dari pola persebaran di dataran tinggi Kerinci, yang daerahnya terdekat dengan Gunung api penduduk mendirikan pemukiman didasari dengan kecukupan sumber air yang baik, dengan mata pencarian penduduk sebagian besar dibidang pertanian, berladang, dan pertanian.

Kersik Tua Merupaka Desa Yang telah sejak lama ada menyangga pariwisata Gunung kerinci, juga sebagai Desa transit para wisatawan yang hendak melakukan pendakian 
gunung kerinci. Tidak di ketahui secara pasti sejak kapan Desa Kersik Tuo menjadi Penyangga dari salah satu Bangunan Homstay sudah ada sejak tahun 1990, perkembangan pariwisata Gunung kerinci kian meningktat dari tahun 2013-2018, diiringi dengan bertambanya jumlah masyarakat yang berpartisipasi dalam menyangga pariwisata dari berbagai sektor, seperti usaha jasa, perdagangan dll, begitu pula dengan perkembangan sosial ekonomi masyarakat penyangga pariwisata, dan masyarakat menyadari pariwisata berperan penting dalam perkembangan desa Kersik Tua, Kedatangan Wisatawan membawa Dampak terhadap perubahan sosial ekonomi masyarakat.

\section{Perkembangan Desa Kersik}

Tua sebagai Desa penyangga Pariwisata Gunung Kerinci yang di kelola Balai Besar Taman Nasional Kerinci Seblat (BBTNKS), dimana keuntungan masuk kedalam kas Negara melalui Penerimaan Negara
Bukan Pajak (PNBP), Pada September 2017 BBTNKS dengan Bupati Kerinci melakukan kerjasama dibidang penguatan fungsi kawasan konservasi Taman Nasional Kerinci Seblat, khususnya mengenai Pengembangan Objek Wisata Gunung Tujuh Dan Gunung Kerinci Pada Zona Pemanfaatan TNKS . Perjanjian kerjasama mengenai penguatan fungsi ini bertujuan untuk meningkatkan pengembangan objek wisata Gunung Tujuh dan Gunung Kerinci pada zona pemanfaatan TNKS di Kabupaten Kerinci Provinsi Jambi berdasarkan kaidah konservasi serta mendukung pemberdayaan Masyarakat dan Pengembangan Ekonomi Daerah Kabupaten Kerinci melalui pengembangan Pariwisata Alam.

\section{DAFTAR PUSTAKA}

Badan Pusat Statistik Kabupaten Kerinci Tahun 2015

Pitana, Gde., \& Diarta, I Ketut Surya. 2009, Pengantar Ilmu Pariwisata, CV. Andi Offset, Yogyakarta. 
JURNAL HORIZON PENDIDIKAN

Publish by: Library of STKIP PGRI Sumatera Barat

E-ISSN : 2775-5770

Vol. 1 No. 2 (Mei 2021) (345-355)

http://ejournal.stkip-pgri-sumbar.ac.id/index.php/horizon

Rai, Gusti Bagas. (2014) Pengantar Industri Pariwisata, Yogyakarta: CV BUDI UTAMA.

Sjamsuddin, Helius. (2012) Metodologi Sejarah Djogjakarta, Ombak

Zed, Mestika. (1999) Metodologi Sejarah, Diktat (Padang: Fakultas Ilmu Sosial Universitas Negeri Padang).

Zetra, Aidinil .(2018) Jurnal

Administrasi dan Kebijakan

Publik Vol. III Tentang

Penetapan Kawasan Strategis

Pariwisata Nasional Kerinci

Sebagai Branding Pariwisata

Provinsi Jambi. 